\title{
END-STAGE RENAL DISEASE IN 1528 CHILDHOOD-ONSET SYSTEMIC LUPUS ERYTHEMATOSUS PATIENTS
}

Ana Paula Sakamoto1,*, Clovis A Silva², Aline Garcia Islabão³, Glaucia Vanessa Novak², Beatriz Molinari², Paulo K Nogueira', Rosa Maria Rodrigues Pereira², Claudia Saad-Magalhães ${ }^{4}$, Ana Flavia S Pina ${ }^{1}$, Gleice Clemente ${ }^{1}$, Daniela P Piotto ${ }^{1}$, Nadia Emi Aikawa ${ }^{2}$, Ana C Pita ${ }^{2}$, Vitor C. Trindade ${ }^{2}$, Simone Appenzeller ${ }^{5}$, Luciana M Carvalho ${ }^{6}$, Carlos Nobre Rabelo-Junior ${ }^{7}$, Adriana R Fonseca ${ }^{8}$, Flavio Roberto Sztajnbok ${ }^{9}$, Maria Carolina Santos ${ }^{10}$, Blanca E Bica ${ }^{8}$, Evaldo G Sena ${ }^{11}$, Ana J Moraes ${ }^{12}$, Melissa Mariti Fraga ${ }^{13}$, Teresa C Robazzi ${ }^{14}$, Paulo Fernando Spelling ${ }^{15}$, Ilóite Maria Scheibe ${ }^{16}$, Andre de Souza Cavalcanti ${ }^{17}$, Erica N Matos ${ }^{18}$, Luciano J Guimarães ${ }^{19}$, Flavia P Santos ${ }^{20}$, Licia Maria Henrique da Mota ${ }^{19}$, Eloisa Bonfá2 ${ }^{2}$ Maria T Terreri ${ }^{1}$

1.Universidade Federal de São Paulo, São Paulo (SP), Brazil; 2.Universidade de São Paulo, São Paulo (SP), Brazil; 3.Hospital da Criança de Brasília José Alencar, Brasília (DF), Brazil; 4.Universidade Estadual Paulista "Júlio de Mesquita Filho", Botucatu (SP), Brazil; 5.Universidade Estadual de Campinas, Campinas (SP), Brazil; 6.Universidade de São Paulo, Ribeirão Preto (SP), Brazil; 7.Hospital Geral de Fortaleza, Fortaleza (CE), Brazil; 8.Universidade Federal do Rio de Janeiro, Rio de Janeiro (RJ), Brazil; 9.Universidade do Estado do Rio de Janeiro, Rio de Janeiro (RJ), Brazil; 10.Irmandade da Santa Casa de Misericórdia de São Paulo, São Paulo (SP), Brazil; 11.Universidade Federal da Paraíba, João Pessoa (PB), Brazil; 12.Universidade Federal do Pará, Belém (PA), Brazil; 13.Hospital Infantil Darcy Vargas, São Paulo (SP), Brazil; 14.Universidade Federal da Bahia, Salvador (BA), Brazil; 15.Instituto Presbiteriano Mackenzie, Curitiba (PR), Brazil; 16. Hospital Criança Conceição, Porto Alegre (RS), Brazil; 17.Universidade Federal de Pernambuco, Recife (PE), Brazil; 18.Universidade Federal de Mato Grosso do Sul, Campo Grande (MS), Brazil; 19.Universidade de Brasília, Brasília (DF), Brazil; 20.Universidade Federal de Minas Gerais, Belo Horizonte (MG), Brazil.

*Corresponding author: anapaula_skmt@yahoo.com

\section{BACKGROUND}

Childhood-onset systemic lupus erythematosus (cSLE) is a multisystemic inflammatory autoimmune disease, usually more severe than in adults, affecting major organs and systems, with different disease presentations, leading to increased morbidity and mortality rates. The study aimed to evaluate end-stage renal disease (ESRD) in a large sample of cSLE patients and to assess its association with clinical and laboratorial characteristics, disease activity, damage accrual, treatment, outcome, and survival.

\section{METHODS}

This nationwide observational study was carried out in 27 Brazilian pediatric rheumatology centers, and includes 1528 cSLE patients. In this study, we also investigated cumulative risk factors for ESRD in cSLE patients.

\section{RESULTS}

A total of 59/1528 (3.9\%) of patients presented ESRD. After Bonferroni's correction for multiple comparisons ( $p<0.0013)$, determinants significantly associated with ESRD were urinary biomarkers abnormalities, neuropsychiatric involvement, higher scores of SLEDAI-2K at last visit and SLICC/ACR-DI and its renal domain, as well as the use of intravenous methylprednisolone, oral cyclosporine, intravenous cyclophosphamide, and rituximab. In the regression model analysis, arterial hypertension ( $H R=15.42$, $95 \% \mathrm{Cl}=6.12-38.83, \mathrm{p} \leq 0.0001)$ and biopsy-proven proliferative nephritis $(\mathrm{HR}=2.83,95 \% \mathrm{Cl}=1.70-4.72, \mathrm{p} \leq 0.0001)$ increased the risk of ESRD.

\section{CONCLUSION}

This study showed that cSLE patients with arterial hypertension and biopsy-proven proliferative nephritis exhibited higher hazard rates of progression to poor outcomes. Therefore, those patients could benefit from strict blood pressure control during follow-up, and optimal treatment for lupus nephritis.

\section{KEYWORDS}

Systemic lupus erythematosus, Lupus nephritis, End-stage renal disease, Outcome, Childhood. 